\title{
UTICAJ LINIJATURE RASTER VALJKA NA UNIFORMNOST OTISKA I REPRODUKCIJU BOJE U FLEKSO ŠTAMPI
}

\section{ANALYSIS OF ANILOX ROLL LINE SCREEN VALUE ON PRINT UNIFORMITY AND COLOR REPRODUCTION IN FLEXOGRAPHY}

\author{
Milan Ćurić, Sandra Dedijer, Fakultet tehničkih nauka, Novi Sad
}

\section{Oblast - GRAFIČKO INŽENJERSTVO I DIZAJN}

Kratak sadržaj - Tehnika flekso štampe je danas jedna od vodećih tehnika u grafičkoj industriji. Ono što je izdvaja od ostalih tehnika jeste njena prilagodljivost različitim podlogama.Kako svaka tehnika teži da obezbedi što veći kvalitet otiska, potrebno je kontrolisati sve parametre koji utiču na postizanje istog. Za dobijanje što uniformnijeg otiska flekso štampe služi raster valjak. Tri glavne osobine raster valjka su: ugao graviranja, linijatura $i$ volumen. Njihova kombinacija određuje količinu $i$ preciznost prenošenja boje na podlogu. Ispitivanje ujednačenosti prenosa boje može se izvršiti pomoću različitih metoda, međutim, ovaj rad se fokusira na ispitivanje analiziranjem motlinga u štampi.

Ključne reči: Flekso štampa, raster valjak, motling

Abstract - Nowadays, flexography is one of the leading techniques in the graphic industry. It's adaptability to different types of substrates is what sets flexography aside from other techniques. Since each of the techniques aims at providing higher print quality, it is necessary to control all the parameters which make influence on achieving the before mentioned. Anilox roll is used for getting as much uniform print in flexography. The three main characteristics of the anilox roll are: engraving angle, screen value and volume. The combination of these characteristics determines quantity and precision of color transfer onto the substrate. Examining the color transfer uniformity can be done using different methods; however, this paper focuses on analysis of mottling.

Keywords: Flexography, anilox roll, mottling

\section{UVOD}

Cilj ovog rada jeste ocena uniformnosti površine štampanih uzoraka $\mathrm{i}$ to krupnih nasumičnih varijacija - motling (engl. print mottle) [1]. Ocena uniformnosti je vršena i kroz analizu CIE Lab vrednosti uzoraka koje su dobijene merenjem pomoću spektrofotometra i metodom digitalne analize slike sa skeniranih uzoraka. Pri tome korišćena je GLCM matrica za analizu i to tri parametra koji predstavljaju izlaz date analize: kontrast, energija i homogenost. Takođe, vršeno je utvrđivanje na koji način struktura raster valjka [2] (linijatura i zapremina odnosno teorijski volumen) i CIE Lab vrednosti [3] utiču na dobijanje što uniformnijeg otiska.

\section{NAPOMENA:}

Ovaj rad proistekao je iz master rada čiji mentor je bila dr Sandra Dedijer, docent.
Poslednji segment rada obuhvatao je analizu jačine veze koja se ostvaruje između instrumentalno merenih $\mathrm{i}$ digitalnom analizom dobijenih Lab i Ch vrednosti.

Da bi se ovo postiglo, najpre su skenirane po dve površine za svaki otisak u tri različite rezolucije, a zatim je od svake površine uzimano šest uzoraka. Ovi uzorci su obrađivani u softveru MATLAB R2012b odakle su izvlačene vrednosti parametara, koje su na kraju predstavljene grafički i tabelarno.

\section{REZULTATI I DISKUSIJA}

Eksperimetalni deo rada sastojao se iz više etapa. Sva ispitivanja su vršena na uzorcima štampanim flekso tehnikom štampe. Uzorci su štampani na jednobojnom (cijan), polimernom materijalu prilikom čega je korišćeno 12 različitih raster valjaka sa varijacijama u zapremini, odnosno teorijskom volumenu i linijaturi. Prva etapa istraživanja podrazumevala je ocenu uniformnosti površine štampanih uzoraka. Uniformnost površine štampanog punog tona na otisku je procenjivana preko parametara GLCM matrice koja služi za ocenu motlinga, nasumičnih krupnih varijacija na otisku, a čije su vrednosti prikazane grafički i tabelarno. Sledeća etapa istraživanja podrazumevala je analizu CIE Lab vrednosti uzoraka koje su dobijene merenjem pomoću spektrofotometra i metodom digitalne analize slike sa skeniranih uzoraka, čiji su rezultati zatim upoređivani i takođe predstavljeni grafički i tabelarno. Poslednje ispitivanje obuhvatalo je analizu GLCM parametara (kontrasta, energije i homogenosti) u korelaciji sa L, C i h koordinatama boje.

\subsection{Analiza sekundarnih karakteristika otiska}

\subsubsection{Rezultati i analiza kontrasta}

$\mathrm{Na}$ grafiku prikazanom na slici 1 se vidi da su srednje vrednosti kontrasta za sve vrednosti rezolucija veoma male za sve uzorke osim u slučaju uzoraka 9 i 11 (i 7 kod rezolucije od 600 dpi), što u teorijskom smislu znači da su lokalne varijacije u sivim tonovima slike male. Kako veći teorijski volumen predstavlja i veći nanos boje na površinu, očekivano bi trebalo da se dobije uniformniji otisak sa što manjim kontrastom. Odstupanje uočeno na uzorcima dobijenim pri štampi sa raster valjcima 9, 11 i delimično 7 i 12 mogu biti posledica načina uzorkovanja i obrade rezultata ili pak činjenice da dati teorijski volumen ne odgovara stvarnom volumenu raster valjka. 


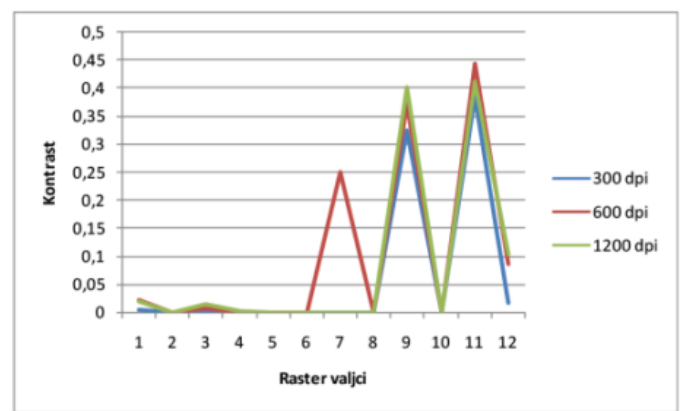

Slika 1. Grafički prikaz rezultata srednjih vrednosti kontrasta svih uzoraka za sve tri rezolucije

\subsubsection{Rezultati i analiza energije}

Imajući u vidu da je energija za konstantnu sliku 1, iz priloženih rezultata većine srednjih vrednosti ovog parametra (slika 2) za sve tri rezolucije koje imaju vrednost približno 1 , jasno je da to definiše ove otiske generalno uniformnim. Ne postoje značajne razlike $\mathrm{u}$ promeni srednje vrednosti parametra sa promenom rezolucije skeniranja, jedino se uzorci 9 i 11 ističu sa niskim vrednostima energije u svim rezolucijama, što ni ne čudi imajući u vidu da se ovi uzorci takođe ističu sa najvišim vrednostima kontrasta, pa su strukturno manje homogeni.

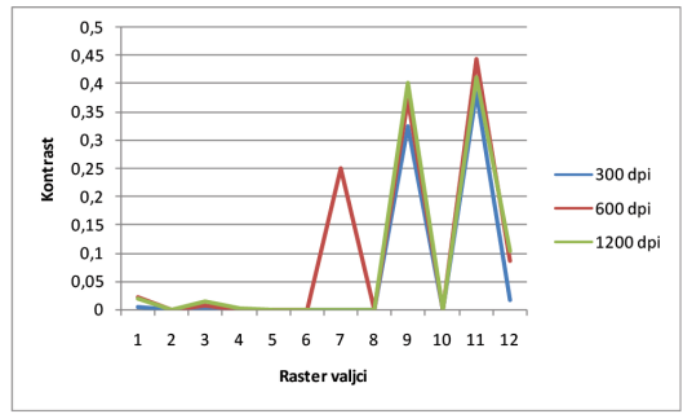

Slika 2. Grafički prikaz rezultata srednjih vrednosti energije svih uzoraka za sve tri rezolucije

\subsubsection{Rezultati i analiza homogenosti}

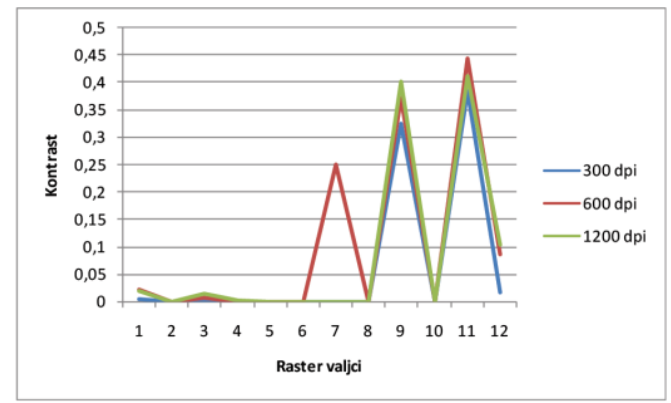

Slika 3. Grafički prikaz rezultata srednjih vrednosti homogenosti svih uzoraka za sve tri rezolucije

Grafik prikazan na slici 3 pokazuje da su svi otisci visoko homogeni. To potvrđuju srednje vrednosti homogenosti svih uzoraka koje su u većini slučajeva približno $1 \mathrm{u}$ svim rezolucijama, uključujući i uzorke 9 i 11, iako su njihove vrednosti, očekivano, nešto niže od ostalih. Ova dva uzorka ujedno imaju i najveće vrednosti kontrasta, a kako su kontrast i homogenost suprotni parametri, logično je da će veća neujednačenost nanosa boje posledično dovesti do smanjenja homogenosti strukture.

\subsection{Analiza svetline i hromatskih vrednosti boje}

$\mathrm{Na}$ osnovu instrumentalnog merenja Lab vrednosti otisaka, formirani su grafički prikazi vrednosti svetline i hromatskih koordinata datih na slici 4.
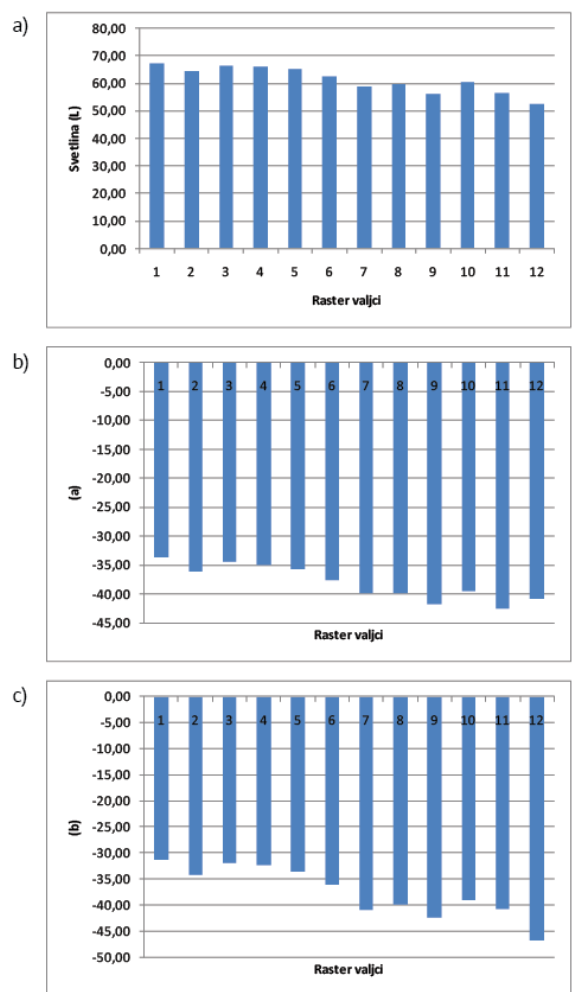

Slika 4.Grafički prikaz rezultata srednjih a) $L$, b) a i c) b vrednosti svih uzoraka

Kao što se može videti na slici 4 sa povećanjem teorijskog volumena, svetlina postepeno opada. Kako hromatske koordinate a i b predstavljaju odnos crveno-zeleno, odnosno žuto-plavo, to se na graficima jasno primeti da dominira zelena, odnosno plava boja pošto one pripadaju negativnom delu ovih dveju skala što je i očekivano s obzirom da je štampa vršena cian bojom. Suprotno svetlini, sa porastom teorijskog volumena zeleni i plavi tonovi postaju sve izraženiji, što se i očekivalo jer su mereni cijan otisci. Pošto je merenje vršeno instrumentalno, spektrofotometrom, ne postoji mogućnost upoređivanja ovih vrednosti sa aspekta rezolucije.

$\mathrm{Na}$ osnovu instrumentalnog merenja hromatičnosti boje (C) i ugla tona boje (h) generisani su grafici koji su prikazani na slikama 5 i 6 .

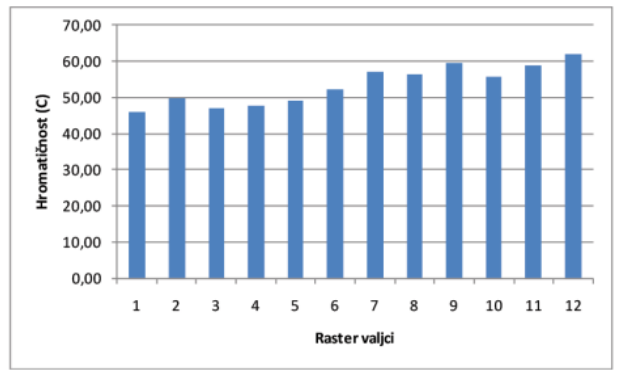

Slika 5.Grafickki prikaz rezultata srednjih vrednosti hromatičnosti svih uzoraka 


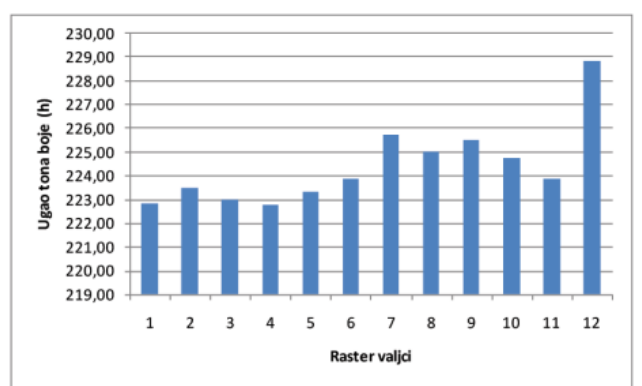

Slika 6.Grafički prikaz rezultata srednjih vrednosti ugla tona svih uzoraka

Hromatičnost boje (slika 5) se kreće u rasponu od 46 do 62, gde se primećuje da blago postepeno raste sa povećanjem teorijskog volumena. Izuzetak čine uzorci $2 \mathrm{i}$ 7, kod kojih se primećuje jači porast, i uzorak 10, čija zasićenost je nešto slabija u kontekstu porasta teorijskog volumena.

Sa druge strane, kod tona boje (slika 6) uočava se mnogo manji opseg vrednosti i kreće se od $223^{\circ}$ do $229^{\circ}$. Uprkos tome što i za ovaj parametar postoji porast vrednosti sa porastom teorijskog volumena, on ovde nije srazmerno povećan jer uzorci 2, 7 i 9 imaju nešto izraženiji porast tona, dok uzorci 8,10 i 11 imaju znatno manji porast u odnosu na prvi uzorak sa najmanjim teorijskim volumenom. Poslednji uzorak sa najvećim teorijskim volumenom ima ujedno i nagli porast tona što znači da je ovaj uzorak najtamniji, odnosno da ima najtamniju nijansu plave. To se moglo zaključiti i na osnovu svetline, jer upravo uzorak 12 ima njenu najmanju vrednost. Ovi dobijeni uglovi tona boje se najbolje vide iz prikaza na krugu boja što je i prikazano na slici 7.

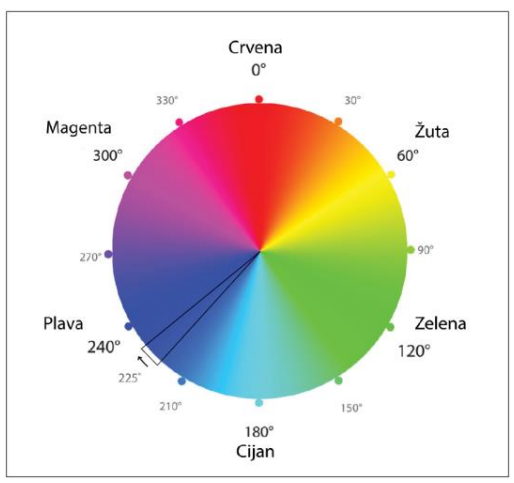

Slika 7.Prikaz ugla tona boje na krugu boja sa naznačenim izmerenim uglom tona boje

\subsection{Analiza kontrasta, energije i homogenosti u korelaciji sa L, c, h koordinatama boje}

$\mathrm{Na}$ osnovu instrumentalnog merenja svetline i srednjih vrednosti kontrasta, energije i homogenosti generisani su grafici koji su prikazani na slici 8 .

Kako korelacioni koeficijent R (slika 8) ima opseg od 0,512 do 0,628 (kontrast), od 0,522 do 0,634 (energija) i od 0,515 do 0,618 (homogenost), na osnovu Chadock skale zaključuje se da svi parametri ostvaruju srednju jačinu veze sa svetlinom, gde se zapaža da ona i kontrast negativno koreliraju, što znači da što je veća svetlina manji je kontrast i obrnuto. U kontekstu rezolucije primećuje se da njenim povećanjem blago raste jačina veze između svih parametara, od kojih najizraženiju vezu sa svetlinom ima energija.
$\mathrm{Na}$ osnovu instrumentalnog merenja hromatičnosti (C) i srednjih vrednosti kontrasta, energije i homogenosti generisani su grafici koji su prikazani na slici 9 .

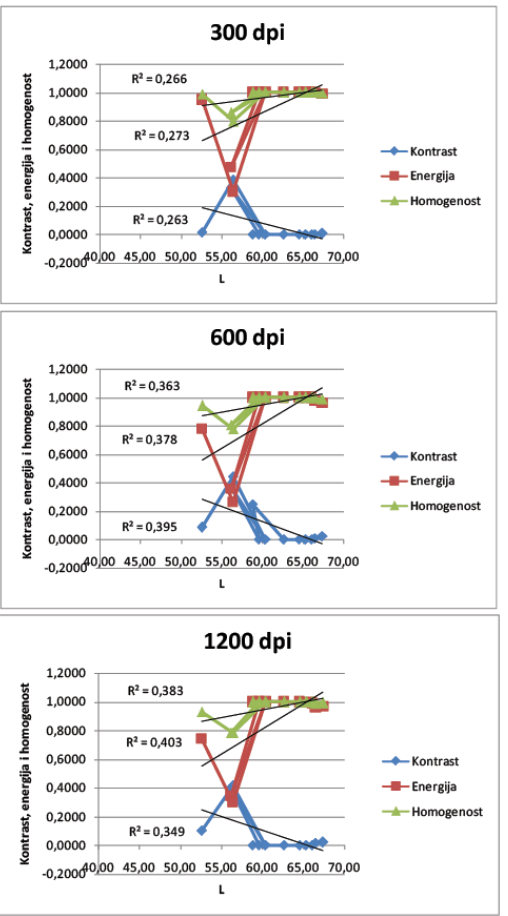

Slika 8.Grafički prikaz rezultata kontrasta, energije $i$ homogenosti u korelaciji sa svetlinom $(L)$ boje i tri rezoucije skeniranja

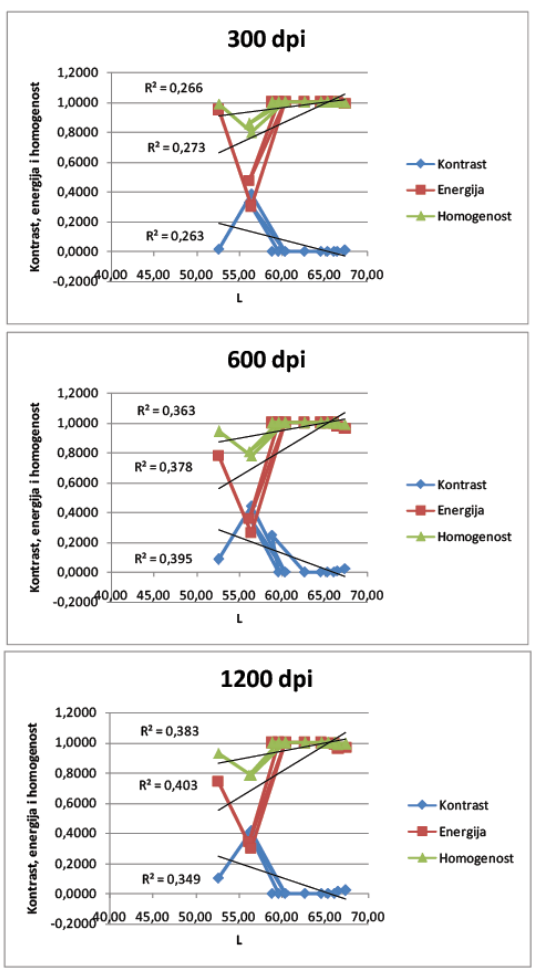

Slika 9.Grafički prikaz rezultata kontrasta, energije i homogenosti u korelaciji sa hromatičnosti (C) boje i tri rezolucije skeniranja

Kako korelacioni koeficijent R (slika 9) ima opseg od 0,5 do 0,622 (kontrast), od 0,505 do 0,6 (energija) i od 0,5 do 0,588 (homogenost), na osnovu Chadock skale zaključuje se da svi parametri ostvaruju srednju jačinu veze sa hro- 
matičnosti, gde se zapaža da ona i energija negativno koreliraju, što znači da što je veća hromatičnost manja je energija i obrnuto. U kontekstu rezolucije primećuje se da njenim povećanjem blago raste jačina veze između svih parametara, od kojih najizraženiju vezu sa hromatičnosti ima kontrast. $\mathrm{Na}$ osnovu instrumentalnog merenja ugla tona boje (h) i srednjih vrednosti kontrasta, energije i homogenosti generisani su grafici koji su prikazani na slici 10.

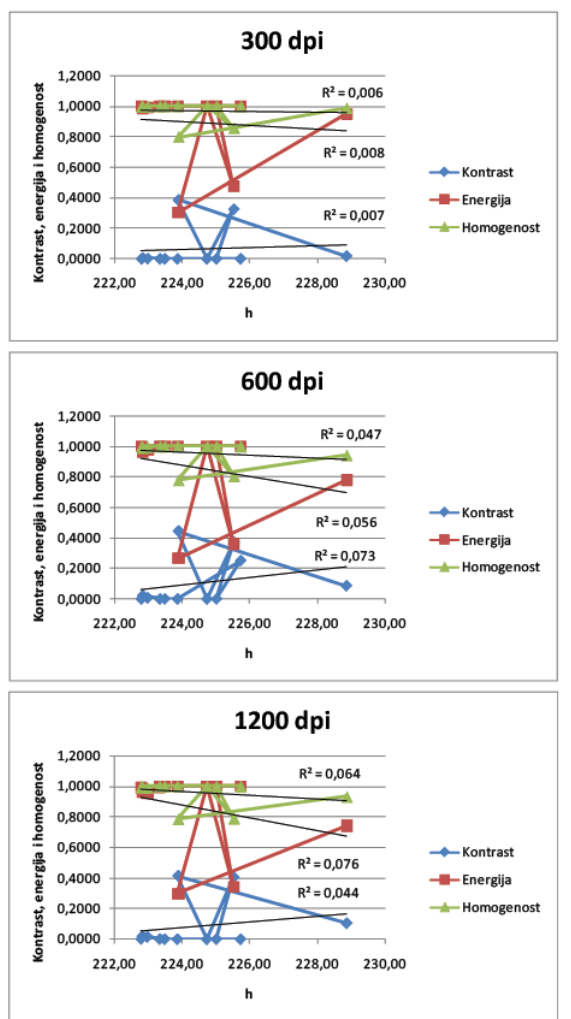

Slika 10.Grafički prikaz rezultata kontrasta, energije $i$ homogenosti u korelaciji sa uglom tona boje (h) $\mathrm{i}$ i tri rezoucije skeniranja

Kako korelacioni koeficijent $\mathrm{R}$ (slika 10) ima opseg od 0,083 do 0,209 (kontrast), od 0,089 do 0,275 (energija) i od 0,077 do 0,252 (homogenost), na osnovu Chadock skale zaključuje se da svi parametri ostvaruju slabu vezu sa uglom tona boje, gde se zapaža da on sa energijom i homogenosti negativno korelira, što znači da što je veća energija ili homogenost manji je ugao tona boje i obrnuto. U kontekstu rezolucije primećuje se da njenim povećanjem blago raste jačina veze između svih parametara, od kojih najizraženiju vezu sa uglom tona boje ima energija.

\section{ZAKLJUČAK}

Prva etapa istraživanja ovog rada podrazumevala je ocenu uniformnosti površine štampanih uzoraka. Zatim se istraživanje nastavilo na analizu CIE Lab vrednosti uzoraka koje su dobijene merenjem pomoću spektrofotometra i metodom digitalne analize slike sa skeniranih uzoraka. Poslednje ispitivanje obuhvatalo je analizu GLCM parametara (kontrasta, energije i homogenosti) u korelaciji sa L, C i h koordinatama boje.

Pokazano je da linijatura i teorijski volumen imaju uticaj na reprodukciju punog tona $\mathrm{u}$ kontekstu uniformnosti, najviše kod otisaka sa najvećim teorijskim volumenom $(9$,
11, 12). Uticaj se ogleda u blagom opadanju uniformnosti otisaka dobijenih sa raster valjcima većeg volumena. Povećanjem volumena raster valjka povećava se i nanos boje, a kako su rezultati pokazali, ujedno i verovatnoća da će taj nanos biti neujednačeniji što dovodi do povećanja kontrasta, a opadanja energije i homogenosti. Kada se otisci posmatraju u kontekstu korišćene rezolucije pri skeniranju, jedino se u slučaju kontrasta mogu uočiti značajne razlike sa povećanjem rezolucije skeniranja, i to na način da se kontrast postepeno smanjuje. Bitno je naglasiti da je analiza pokazala često dosta visoku vrednost koeficijenta varijacije za dobijene rezultate, što može biti posledica načina samog uzorkovanja slika ili obrade slika u MATLABu.

Kao najuniformniji otisci izdvajaju se uzorci 2, 5 i 6, dok su se uzorci 9 i 11 pokazali kao najmanje uniformni. Pokazano je takođe da linijatura i teorijski volumen imaju uticaj i na Lab i Ch vrednosti uzoraka, i to takav da sa povećanjem teorijskog volumena svetlina postepeno opada, dok a i b komponente boje postepeno rastu. Primećeno je da hromatičnost (C) i ugao tona boje (h) takođe imaju porast vrednosti, ali on nije linearan kao kod Lab vrednosti. Uzimajući sve parametre u obzir utvrđeno je da uzorci 2 i 7 imaju najlošiji odnos ovih parametara, dok uzorci 8, 9 i 10 najbolji. Sa stanovišta jačine veze koja se ostvaruje između instrumentalno merenih i digitalnom analizom dobijenih Lab i Ch vrednosti, pokazano je da svaka od ovih vrednosti ostvaruje čvrstu vezu prema Chadock skali što znači da izmerene vrednosti izuzetno dobro koreliraju sa vrednostima dobijenim digitalnom analizom slike.

To dalje znači da su obe tehnike merenja pogodne za izvlačenje Lab vrednosti i da obe mogu da se koriste bez značajnijih razlika u dobijenim vrednostima. Rezolucija nema nikakav uticaj na promenu Lab parametara, jer je njenim povećanjem primećen veoma mali porast korelacionog koeficijenta, ali je on zanemarljiv. Kod ispitivanja korelacije GLCM parametara sa LCh vrednostima pokazano je da sva tri parametra (kontrast, energija i homogenost) ostvaruju srednju jačinu veze sa svetlinom i hromatičnosti, i slabu vezu sa uglom tona boje kroz sve tri rezolucije. Porastom rezolucije blago raste jačina veze između svih parametara, od kojih najizraženiju vezu sa LCh vrednostima ostvaruje energija: pozitivnu vezu sa L i negativnu sa $\mathrm{C}$ i h.

\section{LITERATURA}

[1] E. Ericcson, "Characterizing banding phenomena in flexoprinted corrugated board", Thesis. Norrkoping, Linköpings Universitet, 2013.

[2] J. Johnson, "The Influence of Moisture, Temperature, Pressure Pulse and Substrate on Print Quality in Flexographic Printing”, Licentiate thesis. Karlstad University, Faculty of Technology and Science Chemical Engineering, 2003.

[3] https://cdn-s3.sappi.com/s3fspublic/sappietc/Defining\%20and\%20Communicating \%20Color.pdf (pristupljeno u oktobru 2018.)

\section{Kontakt:}

Milan Ćurić, milancuric94@yahoo.com

Sandra Dedijer, dedijer@uns.ac.rs 